Article

\title{
Sound Absorption Characteristics of Aluminum Foams Treated by Plasma Electrolytic Oxidation
}

\author{
Wei Jin ${ }^{1}$, Jiaan Liu ${ }^{1, *}$, Zhili Wang ${ }^{1}$, Yonghua Wang ${ }^{2,3}$, Zheng Cao ${ }^{1}$, Yaohui Liu ${ }^{1}$ and \\ Xianyong Zhu ${ }^{1}$
}

Received: 27 July 2015 ; Accepted: 15 October 2015 ; Published: 9 November 2015

Academic Editor: Sven De Schampheleire

1 Key Laboratory of Automobile Materials (Ministry of Education), College of Materials Science and Engineering, Jilin University, Changchun 130022, China; Jinweiking2005@163.com (W.J.); Wangzl@mail.jlu.edu.cn (Z.W.); Caozheng@163.com (Z.C.); Liuyh@mail.jlu.edu.cn (Y.L.); Zhuxy@jlu.edu.cn (X.Z.)

2 Key Laboratory of Bionic Engineering (Ministry of Education), Jilin University, Changchun 130022, China; Wangyh@mail.jlu.edu.cn

3 School of Mechanical and Electric Engineering, Changchun University of Science and Technology, Changchun 130022, China

* Correspondence: liuja@jlu.edu.cn or thiamine@163.com; Tel.: +86-431-8509-5862; Fax: +86-431-8509-5235

\begin{abstract}
Open-celled aluminum foams with different pore sizes were fabricated. A plasma electrolytic oxidation (PEO) treatment was applied on the aluminum foams to create a layer of ceramic coating. The sound absorption coefficients of the foams were measured by an impedance tube and they were calculated by a transfer function method. The experimental results show that the sound absorption coefficient of the foam increases gradually with the decrease of pore size. Additionally, when the porosity of the foam increases, the sound absorption coefficient also increases. The PEO coating surface is rough and porous, which is beneficial for improvement in sound absorption. After PEO treatment, the maximum sound absorption of the foam is improved to some extent.
\end{abstract}

Keywords: foams; aluminum; plasma electrolytic oxidation; sound absorption

\section{Introduction}

Aluminum foams with open-cell structure have many outstanding physical and mechanical properties, such as low density, high damping properties, and excellent sound absorption [1,2]. These advantages make aluminum foams suitable for application in many fields, including transportation, electronics, and the aerospace industry [1-3].

There are increasing studies on the sound absorption characteristics of the aluminum foams [4-9]. Lu et al. presented an experimental and theoretical study for the sound absorption of aluminum foams with semi-open cells. The theoretical model revealed the correlation between sound absorption and morphological parameters such as pore size, pore opening, and porosity [4]. Li et al. fabricated aluminum foams with spherical cells by an infiltration process. They found sound absorption increases with an increase in the number of pore openings or with a decreased diameter of the pore openings [5]. Wang found that the sound absorption behavior of open-celled aluminum foam was correlated with the pore size, sample thickness, and backing air gap depth. As frequency or sample thickness increases, the sound absorption is significantly enhanced [6]. Masataka Hakamada fabricated the aluminum foams with porosities of $85 \%-95 \%$ by the spacer method. The sound absorption coefficient increased with porosity and thickness. However, they found that there was no apparent correlation between the pore size and sound absorption coefficient [7]. The sound 
absorption coefficient of the aluminum is significantly improved by inserting an air gap between the tested sample and the back surface [5,8]. Recently, Ren synthesized ZnO micro-rods on the cell walls of open-celled aluminum foams. The experiment showed that the sound absorption coefficient increased about $40 \%$ at maximum, which indicates that the sound absorption characteristics of aluminum foams can be improved by surface treatment [9].

Though some studies were carried out on the sound absorption of aluminum foams, the studies for the purpose of improving the sound absorption by using a surface treatment method are still shown to be deficient. Therefore, in this study, the plasma electrolytic oxidation (PEO) treatment [10], also named micro-arc oxidation (MAO) [11,12], was applied on the aluminum foams, and the morphology, structure, and sound absorption characteristic of the foams were investigated.

\section{Results and Discussion}

\subsection{Morphology of the Foams}

Figure 1 shows the typical morphology of the Al foams. The pores of the foams are spheroidal. These foams have different pore sizes which were counted by digital image software. The foams are classified by the mean pore size for the measurements of the sound absorption coefficient. The mean pore sizes of the foams marked digitally from 1 to 6 are $\sim 4.48, \sim 5.18, \sim 5.70, \sim 3.52, \sim 3.08$, and $\sim 3.32 \mathrm{~mm}$, respectively. Additionally, the porosities of the foams marked digitally from 1 to 6 are $\sim 65 \%, \sim 76 \%, \sim 77 \%, \sim 75 \%, \sim 73 \%$, and $\sim 66 \%$, respectively. Figure 2 shows the microstructure of the Al foams. It can be seen from Figure 2 that the small pore openings exist on the cell walls that form the interconnected channels among the foams' pores, which is similar to the foams reported by Li [5].



Figure 1. Typical morphology of the $\mathrm{Al}$ foams used for the sound absorption test.

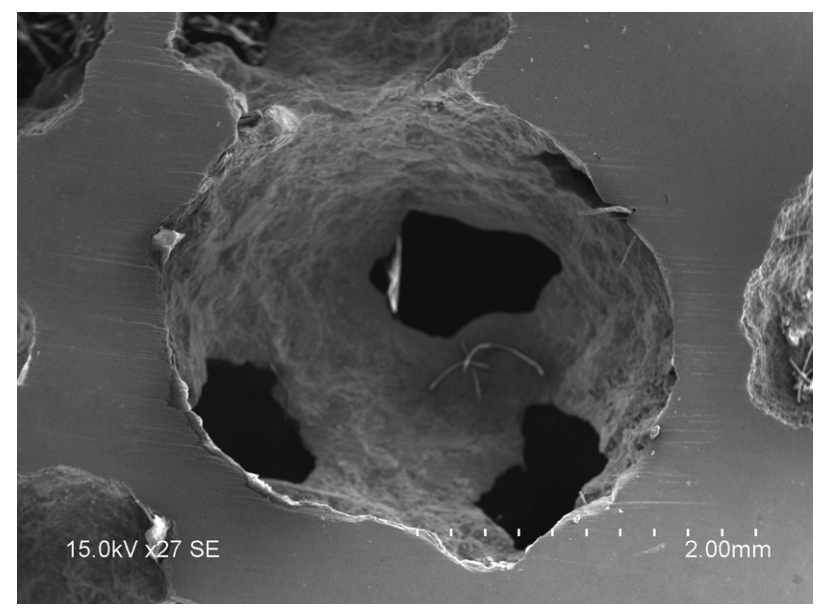

Figure 2. SEM of typical microstructure of the $\mathrm{Al}$ foams. 


\subsection{Microstructure of the PEO Coating}

The SEM images of PEO coatings on the foams are shown in Figure 3. It can be seen that the coating surface is rough and porous, i.e., there are some micro-pores on the surface, which results from the micro-arc discharges [13-16]. During the PEO process, the micro-arc discharges happen constantly. When a micro-arc extinguishes, it will leave a micro-pore on the surface. Therefore, the PEO coatings show a porous and rough surface. Figure 4 shows an SEM image of a cross-section of PEO coating and its EDS analysis. It can be seen that the PEO coatings are mainly composed of aluminum and oxygen. Additionally, the thickness of the PEO coating is about $6.3 \mu \mathrm{m}$. Therefore, after PEO treatment, the pore size change can be negligible in the present $\mathrm{Al}$ foams.


Figure 3. SEM images of the PEO coatings on the foams: (b) magnification of (a), (c) and (d) magnification of $(\mathbf{b})$.
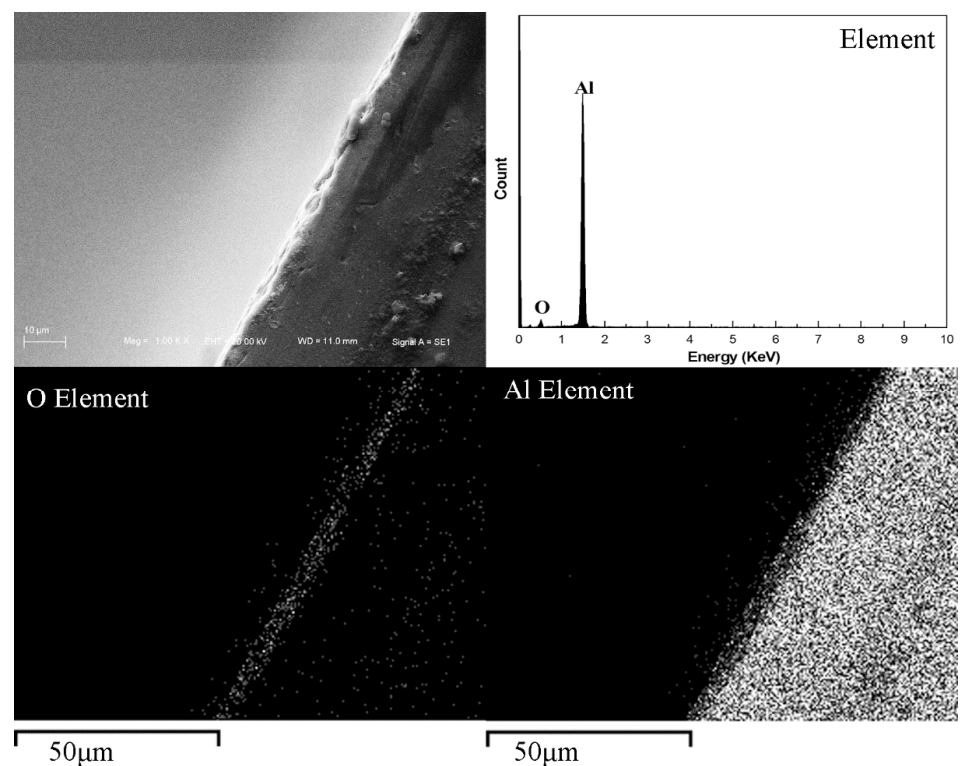

Figure 4. SEM image of cross-section of PEO coating and its EDS analysis. 


\subsection{XRD Study of the PEO Coating}

The XRD diffraction pattern of the coated $\mathrm{Al}$ foams is shown in Figure 5. It is clear that the major phase in the PEO coatings is $\gamma-\mathrm{Al}_{2} \mathrm{O}_{3}$. The presence of the $\mathrm{Al}$ pattern is due to the substrate material.

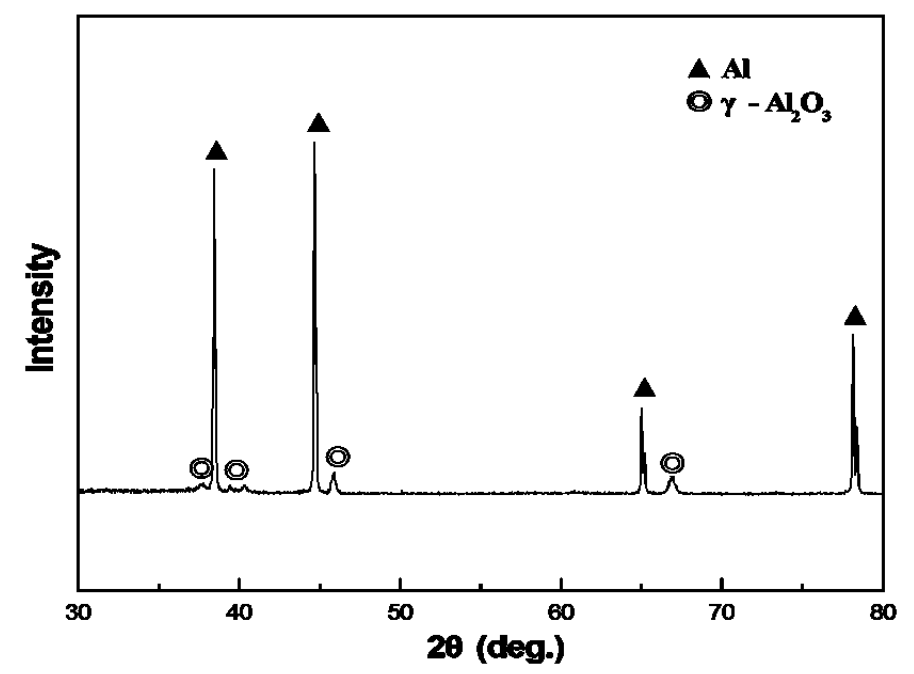

Figure 5. XRD pattern of the PEO-coated Al foams.

\subsection{Sound Absorption Characteristics}

\subsubsection{Effect of Pore Size on the Sound Absorption of the Foams}

Figure 6 shows the sound absorption of the foams with different pore sizes and approximately uniform porosities (around 73\%) and thicknesses (around $2.25 \mathrm{~cm}$ ) in the frequency range of 1000-6000 Hz. From Figure 6, it can be concluded that the sound absorption of the foams is increasing with decreasing pore sizes. Therefore, it is concluded that relatively small pores of the foams are beneficial to sound absorption. This tendency is consistent with those observed in aluminum foams [4-6].



Figure 6. Sound absorption coefficient $v$ s. frequency of the foams with different mean pore sizes.

\subsubsection{Effect of Porosity on Sound Absorption of the Foams}

Figure 7 shows the sound absorption curves of the foams with different porosities and approximately uniform mean pore sizes (around $5.7 \mathrm{~mm}$ ) and thicknesses (around $2.7 \mathrm{~cm}$ ). As shown 
in Figure 7, the sound absorption coefficient increases when the porosity changes from $66 \%$ to $75 \%$, demonstrating that the foam with high porosity is a good sound absorber.



Figure 7. Sound absorption coefficient $v$ s. frequency of the foams with different porosities.

\subsubsection{Effect of PEO Treatment on Sound Absorption of the Foams}

Figure 8 shows the sound absorption curves of the foams with PEO treatment. It can be found that the sound absorption peak increased by $\sim 5.5 \%$ after the PEO treatment. As mentioned above, two mechanisms are responsible for the sound absorption characteristics of $\mathrm{Al}$ foams, i.e., the viscous losses resulting from the air flow and the thermal losses originating from the friction between the air and the cell wall through the vibration of air in the pores [4-6,9]. It can be found after the PEO treatment that there are small pores at micrometer level distributed in the surface of the aluminum foams. These small pores add a transport path of the sound wave and increase the flow resistance of the sound wave. Therefore, it is obvious that the rough and porous coating will enhance the interaction between the air and the pore, not only in the friction force but also the thermal exchange, which raises the sound wave loss. It is also noted that the displacement of the absorption peak shifted to the right a bit. It can be inferred that the displacement of the absorption peak might be attributed to the complex effect of change of the foam structure.

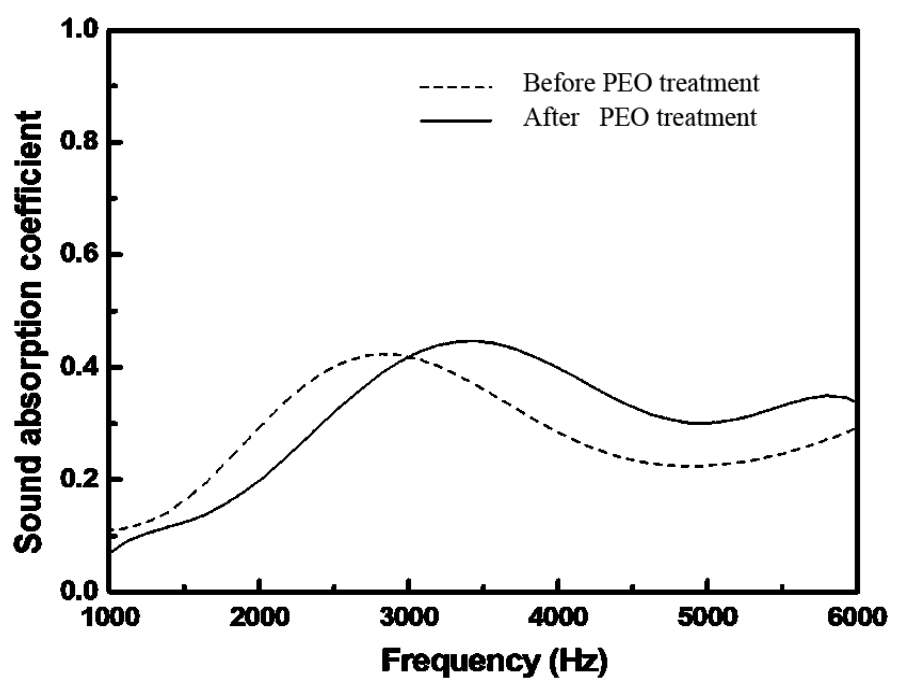

Figure 8. Sound absorption coefficient $v$ s. frequency of the foams with PEO treatment. 


\section{Experimental Section}

\subsection{Preparation and PEO Treatment of the Foams}

Pure aluminum was used as raw material to prepare the foams. The calcium chloride preform was fabricated according to the following procedure: the spheroidal calcium chloride particles (>99\% pure) were blended with inorganic binder in a mold to form a mixture, which was later dried out at about $260-350{ }^{\circ} \mathrm{C}$. The porous preform was then sintered at about $580-650{ }^{\circ} \mathrm{C}$. To make the foams, the calcium chloride preform was infiltrated with the molten $\mathrm{Al}$ melted at about $680-740{ }^{\circ} \mathrm{C}$. Different process parameters could be applied to obtain $\mathrm{Al}$ foams with different densities and pore sizes [17].

The foam samples were PEO-coated using an alternating current power source and an alkali electrolyte. The electrolysis environment was an aqueous electrolyte containing $\mathrm{NaOH}$ and $\mathrm{Na}_{2} \mathrm{SiO}_{3}$ at concentrations of $4 \mathrm{~g} / \mathrm{L}$ and $9 \mathrm{~g} / \mathrm{L}$, respectively. The working frequency of PEO oxidation experiments was $500 \mathrm{~Hz}$. During the coating process, the temperature of the electrolyte was maintained constant at approximately $30{ }^{\circ} \mathrm{C}$ using a stirring and cooling system [18].

\subsection{Material Characterization}

The porosities of the $\mathrm{Al}$ foams were calculated using the following equation:

$$
P=\left(1-\rho^{*} / \rho_{\mathrm{s}}\right) \times 100 \%
$$

where $P$ is the porosity of the foams; $\rho^{*}$ and $\rho_{\mathrm{s}}$ are the densities of the foams and the cell wall material, respectively; and $\rho^{*} / \rho_{\mathrm{S}}$, which is called the relative density of the foams, indicates the ratio of the density of the foams to the density of the cell wall material.

The pore size of the foam was obtained by digital image processing software (Nano Measurer series) from optical images of the foams. The microstructure of the foams and PEO coating were observed by scanning electron microscopy (SEM) (Model JSM-5310, Tokyo, Japan). The different elements in the composites were analyzed by the energy-dispersive $\mathrm{X}$-ray spectroscopy (EDS) (Model X-Max, Oxford, UK). The phases were analyzed by X-ray diffraction (XRD) (Model D/Max 2500PC Rigaku, Tokyo, Japan). The wavelength used was $\mathrm{Cu} \mathrm{Ka}$ and it was scanned from $30^{\circ}$ to $80^{\circ}$ with a scan speed of $1 \mathrm{~s} /$ step.

\subsection{Measurements of Sound Absorption Coefficient}

There are two main types of methods for determining the absorption coefficient of acoustic materials: the reverberation time method for a diffuse field, and the impedance tube method for a normal incidence. In this investigation, the sound absorption coefficients of foams were measured by using the impedance tube. Therefore, the "absorption coefficient" measured in this study is the "sound absorption coefficient at normal incidence". The impedance tube is manufactured by BSWA TECH (SW series), as shown in Figure 9. Broadband random sound waves were generated by the loudspeaker at one end of the impedance tube and transmitted to the surface of the sample at the other end. The reflected signals were picked up by the sensors. The diameter of the tested sample is $30 \mathrm{~mm}$. The date was measured by applying the transfer function method due to its reproducibility. The data collected by the computer system were then used to plot the sound absorption coefficient frequency $(1000-6000 \mathrm{~Hz})$ curves. In order to ascertain reproducibility, each tested result was the average obtained from more than three tested specimens. 




Figure 9. The impedance tube devices.

\section{Conclusions}

In this paper, the sound absorption characteristics of aluminum foams have been evaluated. PEO treatment was applied on the foams to deposit a layer of coating. The PEO coating is rough and porous. In the PEO coating, $\gamma-\mathrm{Al}_{2} \mathrm{O}_{3}$ is present as the major phase. The sound absorption increases gradually with the decrease of pore size or the rise of porosity. The maximum sound absorption coefficient increases by $\sim 5.5 \%$ after the PEO treatment. The improvement is attributed to the micro-pores and the rough surface that enhances the sound wave loss by increasing the friction between the surface and the air.

Acknowledgments: This work is supported by "The National Natural Science Foundation of China (No.51201068)", "The Science and Technology Development Projects of Jilin Province (Nos. 201201032, 20130204017GX and 20150307037GX)", "The Fundamental Research Funds for the Central Universities (Jilin University, No. 2013ZY04)" and "The Science and Technology Projects of Changchun City (No. 12ZX29)".

Author Contributions: The sound absorption tests were carried out by Zhili Wang, Yonghua Wang and Wei Jin. The SEM and XRD characterization were performed by Jiaan Liu with the participation of Wei Jin, Zhili Wang and Zheng Cao. The experimental scheme was framed by Yaohui Liu and Xianyong Zhu. The manuscript was composed by Wei Jin and Zhili Wang, and revised by Yonghua Wang and Jiaan Liu.

Conflicts of Interest: The authors declare no conflict of interest.

\section{References}

1. Banhart, J. Manufacture, characterization and application of cellular metals and metal foams. Prog. Mater. Sci. 2001, 46, 559-632. [CrossRef]

2. Gibson, L.J.; Ashby, M.F. Cellular Solids: Structure and Properties, 2nd ed.; Cambridge University Press: Oxford, UK, 1997.

3. Degischer, H.P.; Kriszt, B. Handbook of Cellular Metals: Production, Processing, Applications; Wiley-Vch-Verlag: Weinheim, Germany, 2002.

4. Lu, T.J.; Chen, F.; He, D.P. Sound absorption of cellular metals with semiopen cells. J. Acoust. Soc. Am. 2000, 4, 1697-1709. [CrossRef]

5. Li, Y.; Wang, X.; Wang, X.; Ren, Y. Sound absorption characteristics of aluminum foam with spherical cells. J. Appl. Phys. 2011, 110. [CrossRef]

6. Wang, X.F.; Wang, X.F.; Wei, X.; Han, F.S.; Wang, X.L. Sound absorption of open celled aluminium foam fabricated by investment casting method. Mater. Sci. Technol. 2011, 27, 800-804. [CrossRef]

7. Masataka, H.; Tetsunume, K.; Youqing, C.; Hiromu, K.; Mamoru, M. Sound absorption characteristics of porous aluminum fabricated by spacer method. J. Appl. Phys. 2006, 100. [CrossRef]

8. Masataka, H.; Tetsunume, K.; Youqing, C.; Hiromu, K.; Mamoru, M. High sound absorption of porous aluminum fabricated by spacer method. Appl. Phys. Lett. 2006, 88. [CrossRef]

9. Ren, Y.; Wang, K.; Zhu, B.; Wang, X.F.; Wang, X.F.; Han, F.S. Synthesis of ZnO micro-rods on the cell walls of open celled Al foam and their effect on the sound absorption behavior. Mater. Lett. 2013, 91, 242-244. [CrossRef] 
10. Khan, R.H.U.; Yerokhin, A.; Li, X.; Dong, H.; Matthews, A. Surface characterisation of DC plasma electrolytic oxidation treated 6082 aluminium alloy: Effect of current density and electrolyte concentration. Surf. Coat. Technol. 2010, 205, 1679-1688. [CrossRef]

11. Li, H.X.; Rudnev, V.S.; Zheng, X.H.; Yarovaya, T.P.; Song, R.G. Characterization of $\mathrm{Al}_{2} \mathrm{O}_{3}$ ceramic coatings on 6063 aluminum alloy prepared in borate electrolytes by micro-arc oxidation. J. Alloy Compd. 2008, 462, 99-102. [CrossRef]

12. Yucel, G.; Ali, E.G. The effect of $\mathrm{Zn}$ on the micro arc oxidation coating behavior of synthetic Al-Zn binary alloys. J. Alloy Compd. 2012, 525, 159-165.

13. Cui, S.H.; Han, J.M.; Du, Y.P.; Li, W.J. Corrosion resistance and wear resistance of plasma electrolytic oxidation coatings on metal matrix composites. Surf. Coat. Technol. 2007, 201, 5306-5309. [CrossRef]

14. Nie, X.; Leyland, A.; Song, H.W. Thickness effects on the mechanical properties of micro-arc discharge oxide coatings on aluminium alloys. Surf. Coat. Technol. 1999, 116-119, 1055-1060. [CrossRef]

15. Yan, Y.Y.; Sun, J.F.; Han, Y.; Li, D.C.; Cui, K. Microstructure and bioactivity of Ca, P and Sr doped $\mathrm{TiO}_{2}$ coating formed on porous titanium by micro-arc oxidation. Surf. Coat. Technol. 2010, 205, 1702-1713. [CrossRef]

16. Laleh, M.; Sabour, R.A.; Shahrabi, T.; Shanghi, A. Effect of alumina sol addition to micro-arc oxidation electrolyte on the properties of MAO coatings formed on magnesium alloy AZ91D. J. Alloy Compd. 2010, 496, 548-552. [CrossRef]

17. Liu, J.A.; Gao, F.; Rao, Y.Q.; Liu, Y. Compressive Properties of Aluminum Foams Produced by Replication Route Using Spheroidal Calcium Chloride as Space Holder. Mater. Trans. 2014, 12, 1906-1908. [CrossRef]

18. Liu, J.A.; Zhu, X.Y.; Huang, Z.Q.; Yu, S.R.; Yang, X.Z. Characterization and property of microarc oxidation coatings on open-cell aluminum foams. J. Coat. Technol. Res. 2012, 9, 357-363. [CrossRef]

(C) 2015 by the authors; licensee MDPI, Basel, Switzerland. This article is an open access article distributed under the terms and conditions of the Creative Commons by Attribution (CC-BY) license (http://creativecommons.org/licenses/by/4.0/). 